УДК 546.72

\title{
Optimization of Conditions for Obtaining Stable Hydrosols of Magnetite Nanoparticles
}

\author{
Tatyana V. Trofimova*, \\ Svetlana V. Saykova, Denis V. Karpov, \\ Dmitriy I. Chistyakov and Alexandr Y. Pavlikov \\ Siberian Federal University \\ Krasnoyarsk, Russian Federation
}

Received 13.07.2019, received in revised form 01.09.2019, accepted 27.12.2019

\begin{abstract}
The work is devoted to the study of the influence of reaction parameters on the qualitative and quantitative composition of magnetite nanoparticles. The method of their synthesis is optimized using the method of mathematical planning and processing of experimental data. The mathematical model is obtained. It was established that the molar ratio of iron (II) and (III) ions, the time of preliminary boiling of distilled water for preparing solutions, the presence of an inert atmosphere of nitrogen, as well as an excess of alkali affect the formation of a stoichiometric product. Monophase magnetite nanoparticles with an average diameter of $8-12 \mathrm{~nm}$ were obtained under optimal conditions. The product is characterized by the methods of transmission electron microscopy and X-ray phase analysis. The effect of pretreatment of magnetite nanoparticles with solutions of strong mineral acids on the stability of its hydrosols has been studied by dynamic and electrophoretic light scattering. It was established that the best stabilization is achieved by pretreatment of magnetite with a solution of perchloric acid.
\end{abstract}

Keywords: magnetite, magnetic nanoparticles, hydrosols, synthesis.

Citation: Trofimova T.V., Saykova S.V., Karpov D.V., Chistyakov D.I., Pavlikov A.Y. Optimization of conditions for obtaining stable hydrosols of magnetite nanoparticles, J. Sib. Fed. Univ. Chem., 2020, 13(1), 99-108. DOI: 10.17516/1998-2836-0165

(C) Siberian Federal University. All rights reserved

This work is licensed under a Creative Commons Attribution-NonCommercial 4.0 International License (CC BY-NC 4.0).

* Corresponding author E-mail address: ttv91@mail.ru 


\title{
Оптимизация условий получения стабильных
}

\section{гидрозолей наночастиц магнетита}

\author{
Т.В. Трофимова, С.В. Сайкова, \\ Д.В. Карпов, Д.И. Чистяков, А.Ю. Павликов \\ Сибирский федеральный университет \\ Российская Федерачия, Красноярск
}

\begin{abstract}
Аннотащия. Исследовано влияние реакционных параметров на качественный и количественный состав наночастиц магнетита. Методом математического планирования и обработки результатов экспериментов дробно-факторного эксперимента $2^{7-4}$ оптимизирована методика их синтеза. Установлено, что на образование стехиометричного продукта влияют мольное соотношение ионов железа (II) и (III), время предварительного кипячения дистиллированной воды для приготовления растворов, время продувания растворов азотом, а также избыток щелочи. В найденных оптимальных условиях получены монофазные наночастицы магнетита со средним диаметром 8-12 нм. Продукт охарактеризован методами просвечивающей электронной микроскопии и рентгенофазового анализа. Методами динамического и электрофоретического светорассеяния изучено влияние предварительной обработки наночастиц магнетита растворами сильных минеральных кислот на стабильность его гидрозолей. Установлено, что наилучшая стабилизация золей достигается при предварительной обработке магнетита раствором хлорной кислоты.
\end{abstract}

Ключевые слова: магнетит, магнитные наночастицы, гидрозоли, синтез.

Цитирование: Трофимова Т.В., Оптимизация условий получения стабильных гидрозолей наночастиц магнетита / Т.В. Трофимова, С.В. Сайкова, Д.В. Карпов, Д.И. Чистяков, А.Ю. Павликов // Журн. Сиб. федер. ун-та. Химия, 2020. 13(1). С. 99-108. DOI: $10.17516 / 1998-2836-0165$

Создание магнитных наночастиц (НЧ) на основе магнетита и других оксидных магнитных материалов - приоритетная область развития современной нанотехнологии. Активно развивающейся областью применения таких наночастиц является биомедицина. Так, НЧ $\mathrm{Fe}_{3} \mathrm{O}_{4}$ с однодоменной структурой предложены в качестве контрастирующего средства для магнитно-резонансной томографии, а также как удобные векторы для адресной доставки лекарственных средств в целевые органы и ткани при помощи внешнего магнитного поля [1]. Способность наночастиц магнетита нагреваться при поглощении переменного высокочастотного излучения может быть использована для термотерапии онкологических заболеваний [2].

В отличие от других оксидных магнитных материалов фаза магнетита образуется уже в водном растворе, поэтому для получения наночастиц $\mathrm{Fe}_{3} \mathrm{O}_{4}$ не требуется процедура отжига, неизбежно приводящая к спеканию наночастиц и образованию крупных агломератов, а полученный продукт характеризуется высокой степенью монодисперсности. Однако в присутствии кислорода воздуха магнетит склонен к окислению, приводящему к нарушению стехиометрии 
фазы и образованию новых фаз. Согласно стехиометрии молярное отношение ионов $\mathrm{Fe}^{+2} / \mathrm{Fe}^{+3}$ в $\mathrm{Fe}_{3} \mathrm{O}_{4}$ равно 0,5. Однако железо (II) в нейтральной и щелочной средах легко окисляется кислородом воздуха и растворенным в воде кислородом до железа (III), поэтому при синтезе и в процессе подготовки полученного продукта к дальнейшим исследованиям необходимо контролировать отношение ионов $\mathrm{Fe}^{2+}$ и $\mathrm{Fe}^{3+}$, а также предотвращать окисление путем снижения концентрации кислорода в реакционной среде.

В отсутствие стабилизации золи магнетита постепенно «стареют», то есть самопроизвольно теряют устойчивость и коагулируют. В присутствии некоторых веществ - коагулянтов - данный процесс значительно ускоряется. Дополнительным фактором, снижающим агрегативную устойчивость гидрозолей магнитных частиц, является действие сил магнитного взаимодействия. Стабилизация частиц имеет большое значение при создании магнитных жидкостей и контрастирующих средств, а также при получении гибридных декорированных наночастиц или НЧ типа «ядро-оболочка», поскольку наличие в растворе агломератов препятствует образованию равномерного покрытия.

Стабильность гидрозолей может быть обусловлена двумя основными факторами - электростатическим и стерическим. Стерическая стабилизация дисперсных систем имеет место при адсорбции молекул ПАВ на поверхности наночастиц. В данном случае сближение частиц не происходит из-за сил отталкивания между молекулами ПАВ в поверхностных слоях частиц. Данный тип стабилизации наиболее эффективен, однако иногда наличие в растворе молекул ПАВ нежелательно.

Под электростатической стабилизацией коллоида подразумевается стабилизация за счет взаимного отталкивания одноименно заряженных частиц золя. Заряд на поверхности частицы образуется за счет адсорбции из раствора ионов электролита либо за счет диссоциации поверхностных групп. Наличие в растворе многозарядных ионов $\left(\mathrm{SO}_{4}{ }^{2-}, \mathrm{PO}_{4}{ }^{3-}\right)$, обладающих высокой адсорбционной способностью, согласно принципу Шульце-Гарди, напротив, способствует коагуляции коллоидной системы. Согласно литературным данным [3], для стабилизации коллоидных растворов магнетита успешно применяется обработка растворами сильных кислот.

Целью настоящей работы является оптимизация условий синтеза монофазного наноразмерного магнетита и изучение влияния обработки сильными кислотами на стабильность гидрозолей полученных частиц.

\section{Экспериментальная часть}

Синтез НЧ магнетита осуществляли методом химического соосаждения, взяв за основу методику [4]. В качестве осадителя использовали раствор $\mathrm{NaOH}$ (100 мл) заданной концентрации. В некоторых опытах к осадителю добавляли слабый восстановитель - 1 М раствор аскорбиновой кислоты. К раствору осадителя при постоянном перемешивании приливали 55 мл раствора смеси солей $\mathrm{FeCl}_{3} \cdot 6 \mathrm{H}_{2} \mathrm{O}$ и $\mathrm{FeCl}_{2} \cdot 7 \mathrm{H}_{2} \mathrm{O}$, взятых в определенном молярном отношении. В зависимости от условий эксперимента в некоторых случаях для удаления кислорода из реакционной зоны воду для приготовления исходных реагентов кипятили в течение получаса, а осаждение проводили в инертной атмосфере азота (скорость продувания 60 пузырьков в 1 мин, время опыта 30 мин). Полученный осадок оставляли для созревания в изолированных 
условиях на время, определенное параметрами опыта, затем отделяли центрифугированием, промывали дистиллированной водой до $\mathrm{pH}$ 7-8 и высушивали в вакуумном эксикаторе при комнатной температуре.

Анализ состава полученного осадка проводили по следующей методике: навеску ( $\mathrm{m}=$ 0,0200 г) растворяли в $1 \mathrm{M} \mathrm{HCl}$, концентрацию ионов $\mathrm{Fe}^{3+}$ и $\mathrm{Fe}^{2+}$ в данном растворе определяли методами комплексонометрического и иодометрического титрования [5].

При изучении стабильности гидрозолей магнетита к навеске осадка $(0,0375$ г) добавляли 25 мл 2 н. раствора кислоты $\left(\mathrm{HCl}, \mathrm{HNO}_{3}, \mathrm{HClO}_{4}\right.$ и $\left.\mathrm{H}_{2} \mathrm{SO}_{4}\right)$ или воды, выдерживали 5 мин, отделяли осадок центрифугированием (15 мин, 8000 об/мин) и редиспергировали в 50 мл дистиллированной воды. Полученные золи с концентрациями частиц 0,75 и 0,15 г/л (разбавление в 5 раз дистиллированной водой) изучали методами динамического и электрофоретического светорассеяния с использованием прибора ZetasizerNanoZS (MalvernInstruments, Великобритания) на длине волны лазерного излучения 632,8 нм и угле рассеяния $173^{\circ}$. Образцы полученных гидрозолей (1 мл) переносили в пластиковую кювету (l=1см) для измерения.

Фазовый состав образцов определяли методом рентгенофазового анализа на дифрактометpe Shimadzu XDR-600 в CuК $\alpha$-излучении, идентификацию фаз осуществляли с помощью картотеки базы данных Объединенного комитета по стандартам в порошковой дифракции Joint Committee on Powder Diffraction Standards [6, 7].

Микрофотографии образцов получали на электронном микроскопе Hitachi 7700M при ускоряющем напряжении 100 кВ.

\section{Обсуждение результатов}

\section{Оптимизация условий получения наночастиц магнетита}

Синтез магнетита щелочным осаждением можно описать следующим уравнением:

$$
8 \mathrm{NaOH}+2 \mathrm{FeCl}_{3}+\mathrm{FeSO}_{4}=\mathrm{Fe}_{3} \mathrm{O}_{4}+6 \mathrm{NaCl}+\mathrm{Na}_{2} \mathrm{SO}_{4}+4 \mathrm{H}_{2} \mathrm{O}
$$

Поиск оптимальных условий получения наночастиц $\mathrm{Fe}_{3} \mathrm{O}_{4}$ проводили методом математического планирования и обработкой результатов дробного факторного эксперимента ДФЭ $2^{7-4}$ (1/16 реплики полного факторного эксперимента) [8]. В качестве целевой функции ( $\mathrm{Y}_{\mathrm{i}}$ ) использовали величину, рассчитанную по формуле (2), представляющую собой отклонение состава полученного продукта от стехиометрии $\mathrm{Fe}_{3} \mathrm{O}_{4}$ :

$$
\mathrm{Yi}=\frac{n_{F e^{+2} / F e^{3+}}^{\text {экеп }}-0,5}{0,5},
$$

где 0,5 - молярное отношение ионов железа в степенях окисления +2 и +3 в магнетите, имеющем состав, полностью отвечающий стехиометрии.

По нашему мнению, именно эта величина характеризует чистоту полученного материала (стремится к 0 в случае стехиометричного продукта), а следовательно, определяет его магнитные свойства. В качестве независимых переменных $\left(\mathrm{X}_{\mathrm{i}}\right)$ были выбраны факторы, в наибольшей степени влияющие на значение $\mathrm{Y}_{\mathrm{i}}$ (уровни их варьирования приведены в табл. 1): 
$\mathrm{X}_{1}$ - отношение $\mathrm{n}\left(\mathrm{Fe}^{2+}\right) / \mathrm{n}\left(\mathrm{Fe}^{3+}\right)$ в исходной смеси;

$\mathrm{X}_{2}$ - продолжительность кипячения дистиллированной воды, использованной для приготовления исходных растворов, мин;

$\mathrm{X}_{3}$ - проведение соосаждения в атмосфере азота, да/нет;

$\mathrm{X}_{4}$ - объем добавленного восстановителя (аскорбиновая кислота, $\mathrm{C}=1 \mathrm{M}$ );

$\mathrm{X}_{5}$ - температура синтеза, ${ }^{\circ} \mathrm{C}$;

$\mathrm{X}_{6}$ - концентрация $\mathrm{NaOH}, \mathrm{M}$;

$\mathrm{X}_{7}$ - время созревания осадка, ч.

Матрица планирования и полученные значения $\mathrm{Y}_{\mathrm{i}}$ приведены в табл. 2.

При реализации дробно-факторного эксперимента провели две серии опытов, по результатам которых определили средние значения частных откликов ( $\left.\mathrm{Y}_{\mathrm{i}}\right)$, оценили ошибку воспроизводимости каждого опыта, рассчитали коэффициенты уравнения регрессии $\left(\mathrm{b}_{\mathrm{i}}\right)$, порог значимости коэффициентов регрессии $\left(\Delta \mathrm{b}=0,133, \mathrm{~b}_{0}=-0,480\right)$ (табл. 1). Относительная ошибка эксперимента составляет $5 \%$.

Таблица 1. Значения независимых переменных и коэффициентов $\left(\mathrm{b}_{\mathrm{i}}\right)$ полученного уравнения регрессии (значимые коэффициенты подчеркнуты)

Table 1 . The values of independent variables and coefficients $\left(b_{i}\right)$ of the obtained regression equation (significant coefficients are underlined)

\begin{tabular}{|l|c|c|c|c|c|c|c|}
\hline & $\mathrm{X}_{1}$ & $\mathrm{X}_{2}$ & $\mathrm{X}_{3}$ & $\mathrm{X}_{4}$ & $\mathrm{X}_{5}$ & $\mathrm{X}_{6}$ & $\mathrm{X}_{7}$ \\
\hline $\begin{array}{l}\text { Верхний уровень } \\
\text { варьирования }\end{array}$ & $1: 1,75$ & 30 & да & 5 & 60 & 6 & 1,5 \\
\hline $\begin{array}{l}\text { Нижний уровень } \\
\text { варьирования }\end{array}$ & $1: 1$ & 0 & нет & 0 & 40 & 4 & 1 \\
\hline $\mathrm{b}_{\mathrm{i}}$ & $\underline{0,143}$ & $\underline{0,209}$ & $\underline{0,192}$ & 0,057 & 0,052 & 0,015 & $-0,023$ \\
\hline
\end{tabular}

Таблица 2. Матрица планирования ДФЭ $2^{7-4}$, результаты ее реализации и рассчитанные на основании полученного уравнения регрессии значения функции отклика

Table 2. Planning matrix of fractional factorial design, the results of its implementation and the values of response function calculated on the basis of the obtained regression equation

\begin{tabular}{|c|c|c|c|c|c|c|c|c|c|c|}
\hline $\begin{array}{c}\text { Номер } \\
\text { опыта }\end{array}$ & $\mathrm{X}_{0}$ & $\mathrm{X}_{1}$ & $\mathrm{X}_{2}$ & $\mathrm{X}_{3}$ & $\mathrm{X}_{4}$ & $\mathrm{X}_{5}$ & $\mathrm{X}_{6}$ & $\mathrm{X}_{7}$ & Yі эксп. & Yі расч. \\
\hline 1 & + & - & - & - & + & + & + & - & $-0,878$ & $-1,024$ \\
\hline 2 & + & + & - & - & - & - & + & + & $-0,856$ & $-0,739$ \\
\hline 3 & + & - & + & - & - & + & - & + & $-0,649$ & $-0,606$ \\
\hline 4 & + & + & + & - & + & - & - & - & $-0,308$ & $-0,321$ \\
\hline 5 & + & - & - & + & + & - & - & + & $-0,673$ & $-0,640$ \\
\hline 6 & + & + & - & + & - & + & - & - & $-0,351$ & $-0,354$ \\
\hline 7 & + & - & + & + & - & - & + & - & $-0,293$ & $-0,222$ \\
\hline 8 & + & + & + & + & + & + & + & + & 0,164 & 0,063 \\
\hline
\end{tabular}


В результате эксперимента получили уравнение регрессии (3), описывающее влияние исследуемых факторов на состав продукта:

$$
Y i=-0,480+0,143 x_{1}+0,209 x_{2}+0,192 x_{3} \text {. }
$$

Значимыми являются три фактора: исходное отношение $\mathrm{n}\left(\mathrm{Fe}^{2+}\right) / \mathrm{n}\left(\mathrm{Fe}^{3+}\right)$, время кипячения воды для приготовления растворов, проведение осаждения в атмосфере азота (два последних фактора связаны с концентрацией растворенного кислорода в системе). Объем добавленного восстановителя, температура синтеза, концентрация щелочи и время созревания осадка оказывают незначительное влияние на состав образующегося продукта. Адекватность данной модели подтвердили на практике, сравнив экспериментальные результаты с рассчитанными по уравнению регрессии, используя критерии Кохрена $\left(\mathrm{G}_{\text {пр }}=0,38<\mathrm{G}_{\text {теор }}=0,68\right)$ и Стьюдента (табл. 1) [8].

В дальнейших экспериментах реакционные параметры варьировали в направлении, предсказанном моделью, с целью поиска оптимума в новом факторном пространстве (крутое восхождение по Боксу-Уилсону). В результате была предложена усовершенствованная методика синтеза НЧ магнетита: к 100 мл $6 \mathrm{M} \mathrm{NaOH} \mathrm{(1,5} \mathrm{избыток} \mathrm{осадителя)} \mathrm{при} \mathrm{постоянном} \mathrm{перемеши-}$ вании на магнитной мешалке в атмосфере азота добавляют растворенные в 55 мл воды навески $\mathrm{FeCl}_{3} \cdot 6 \mathrm{H}_{2} \mathrm{O}$ и $\mathrm{FeCl}_{2} \cdot 7 \mathrm{H}_{2} \mathrm{O}$ (m $=27,05$ и 12,65 г соответственно), взятые в молярном соотношении $1: 2$, смесь оставляют перемешиваться на 1 ч при температуре $60{ }^{\circ} \mathrm{C}$. Старение осадка в изолированных условиях проводили в течение 1 ч. Воду для приготовления исходных реагентов кипятили в течение 1 ч для снижения концентрации растворенного кислорода.

По данным рентгенофазового анализа (РФА) (рис. 1), в найденных нами оптимальных условиях получен монофазный продукт, соответствующий структуре $\mathrm{Fe}_{3} \mathrm{O}_{4}$ [7].

Размер кристаллитов, рассчитанный по формуле Шеррера, составляет 14 нм. Необходимо учитывать, что при определении размера частиц по рентгенографическим данным возможны погрешности, связанные как с используемым оборудованием (инструментальное уширение пиков, точность юстировки), так и со свойствами самого материала, например дефекты кристаллической решетки также приводят к уширению рентгеновских пиков. Поэтому синтезированный в оптимальных условиях образец $\mathrm{Fe}_{3} \mathrm{O}_{4}$ был исследован методом просвечивающей электронной микроскопии (рис. 2). Полученные результаты хорошо согласуются с величиной, найденной по кристаллографическим данным: частицы магнетита имеют кубическую форму и размеры 8-12 нм.

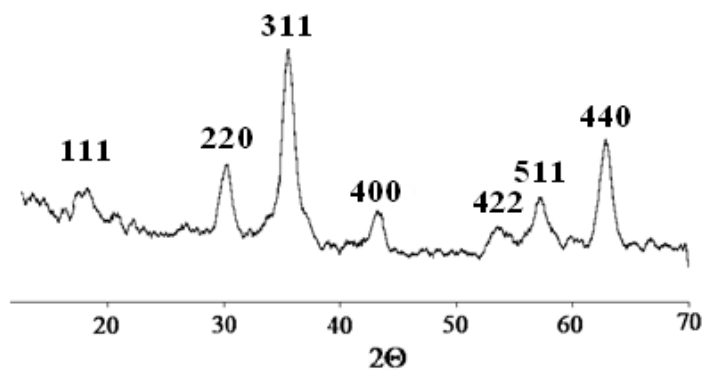

Рис. 1. Рентгенограмма образца $\mathrm{Fe}_{3} \mathrm{O}_{4}$, полученного в оптимальных условиях

Fig. 1. X-ray diffraction pattern of a sample of $\mathrm{Fe}_{3} \mathrm{O}_{4}$ obtained in optimal conditions 


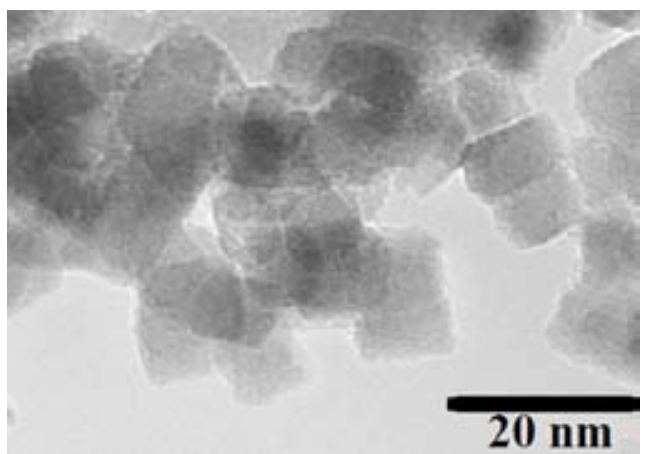

Рис. 2. Микрофотография образца $\mathrm{Fe}_{3} \mathrm{O}_{4}$, полученного в оптимальных условиях

Fig. 2. Micrograph of a sample of $\mathrm{Fe}_{3} \mathrm{O}_{4}$ obtained in optimal conditions

\section{Исследование седиментационной}

\section{и агрегативной устойчивости гидрозолей наночастиц магнетита}

Для исследования влияния обработки кислотой и состава дисперсионной среды на стабильность гидрозолей магнетита использовали полученный в оптимальных условиях продукт и 2 н. растворы $\mathrm{HCl}, \mathrm{HNO}_{3}, \mathrm{HClO}_{4}$ и $\mathrm{H}_{2} \mathrm{SO}_{4}$. Результаты в виде значений гидродинамического диаметра $\left(\mathrm{d}_{\text {гидр }}\right)$ частиц и их поверхностного дзета-потенциала $(\mathrm{Z})$ представлены в табл. 3, там же указаны визуальные изменения исследуемых коллоидных систем во времени.

Как известно [9], на поверхности оксидов в водной среде всегда присутствуют ОН-группы, образование которых обусловлено хемосорбцией молекул воды. Диссоциация поверхностных ОН-групп по кислотному или основному типу вызывает возникновение электрического заряда и образование двойного электрического слоя за счет адсорбции противоионов. Данный механизм ответствен за стабилизацию наночастиц оксидов в водных растворах. Формула мицеллы магнетита в водном растворе в отсутствие стабилизаторов может быть следующая:

Таблица 3. Результаты исследования седиментационной устойчивости гидрозолей магнетита, обработанного минеральными кислотами

Table 3. The results of studies of the sedimentation stability of magnetite hydrosols treated with mineral acids

\begin{tabular}{|c|c|c|c|c|c|}
\hline $\begin{array}{l}\text { Предварительная } \\
\text { обработка }\end{array}$ & $\begin{array}{c}\text { Концентрация } \\
\mathrm{Fe}_{3} \mathrm{O}_{4}, \text { г/л }\end{array}$ & $\mathrm{pH}$ & $\mathrm{Z}, \mathrm{MB}$ & $\begin{array}{c}\mathrm{d}_{\text {гидр }} \\
\text { нм }\end{array}$ & Наблюдения \\
\hline $\mathrm{H}_{2} \mathrm{O}$ & 0,75 & 6,04 & $-31,8$ & 230 & Полная коагуляция, осадок \\
\hline \multirow{2}{*}{$\mathrm{HCl}$} & 0,75 & 2,38 & 49,3 & 113 & \multirow{2}{*}{$\begin{array}{l}\text { Частичная коагуляция, желтая } \\
\text { окраска раствора }\end{array}$} \\
\hline & 0,15 & 2,96 & 55,5 & 202 & \\
\hline \multirow{2}{*}{$\mathrm{HNO}_{3}$} & 0,75 & 2,25 & 51,7 & 133 & \multirow{2}{*}{$\begin{array}{l}\text { Частичная коагуляция, бурая окраска } \\
\text { раствора и осадка }\end{array}$} \\
\hline & 0,15 & 2,83 & 50,1 & 127 & \\
\hline \multirow{2}{*}{$\mathrm{H}_{2} \mathrm{SO}_{4}$} & 0,75 & 2,51 & 7,02 & 2185 & \multirow{2}{*}{$\begin{array}{l}\text { Полная коагуляция, ржаво-бурый } \\
\text { осадок }\end{array}$} \\
\hline & 0,15 & 2,96 & 13,4 & 3768 & \\
\hline \multirow{2}{*}{$\mathrm{HClO}_{4}$} & 0,75 & 2,73 & 29,8 & 111 & \multirow{2}{*}{ Темно-коричневый стабильный золь } \\
\hline & 0,15 & 3,15 & $-20,1$ & 339 & \\
\hline
\end{tabular}




$$
\left\{\mathrm{m}\left(\mathrm{Fe}_{3} \mathrm{O}_{4}\right) \cdot \mathrm{nOH}^{-} \cdot(\mathrm{n}-\mathrm{x}) \mathrm{H}^{+}\right\}^{\mathrm{x}-} \cdot \mathrm{xH}^{+} .
$$

Изменение $\mathrm{pH}$ раствора может приводить к подавлению диссоциации поверхностных ОНгрупп и снижению заряда и дзета-потенциала частиц золя. Значение $\mathrm{pH}$, соответствующее нулевому значению дзета-потенциала, называется точкой нулевого заряда (ТН3). При рН больше ТНЗ золи заряжены отрицательно, при понижении $\mathrm{pH}$ системы падает концентрация ионов $\mathrm{OH}^{-}$в растворе и в потенциалопределяющем слое, что приводит к снижению абсолютной величины дзета-потенциала и сжатию двойного электрического слоя (ДЭС). В ТНЗ ДЭС полностью исчезает, пропадает кулоновский барьер между частицами, и золь коагулирует. Дальнейшее снижение $\mathrm{pH}$ ведет к диссоциации поверхностных групп по основному типу и адсорбции протонов из раствора. Абсолютная величина дзета-потенциала вновь растет, наблюдается пептизация осадка. Таким образом, $\mathrm{pH}$ прямо влияет на строение ДЭС частиц магнетита и величину дзета-потенциала, от которых, в свою очередь, зависит устойчивость золя к коагуляции и седиментации [10].

Как видно из данных табл. 3, частицы магнетита, не подвергавшиеся кислотной обработке, быстро агломерируют и выпадают в осадок, что приводит к значительному уменьшению концентрации наночастиц в жидкой фазе (менее $20 \%$ от исходной концентрации). Измеренные значения дзета-потенциала и гидродинамического диаметра соответствуют небольшой доле НЧ, оставшихся в растворе.

Наночастицы, обработанные кислотой, как было указано выше, должны образовывать более стабильные гидрозоли вследствие формирования положительного заряда на их поверхности. Условно мицеллу магнетита в присутствии кислоты вида $\mathrm{H}_{z} \mathrm{~A}$ можно записать так:

$$
\left\{\mathrm{m}\left(\mathrm{Fe}_{3} \mathrm{O}_{4}\right) \cdot \mathrm{znH}^{+} \cdot(\mathrm{n}-\mathrm{x}) \mathrm{A}^{\mathrm{z}-}\right\}^{\mathrm{zx}+} \cdot \mathrm{xA}^{\mathrm{z}-} .
$$

Однако в случае использования серной кислоты наблюдается значительное увеличение гидродинамического диаметра частиц и выпадение большей их части в осадок. Это объясняется отрицательным влиянием на устойчивость золей сульфат-ионов, обладающих ввиду большого заряда и радиуса (в соответствие с принципом Шульце-Гарди) высокой коагулирующей способностью. Они адсорбируются на поверхности частицы, снижают величину ее дзета-потенциала, устраняя таким образом электростатическое отталкивание между мицеллами золя.

Кроме того, в случае серной и азотной кислот изменение цвета раствора и осадка позволяет говорить о заметном окислении магнетита [11].

При использовании хлороводородной кислоты стабильность золей также невысока, к тому же происходит заметное растворение осадка вследствие образования хлоридных комплексов железа (III). Высокое значение дзета-потенциала соответствует небольшому количеству оставшихся в растворе частиц и, вероятно, обусловлено адсорбцией ионов $\mathrm{Fe}^{3+}$, способных достраивать кристаллическую решетку агрегата в составе мицеллы (правило Фаянса):

$$
\left\{\mathrm{m}\left(\mathrm{Fe}_{3} \mathrm{O}_{4}\right) \cdot \mathrm{nFe}^{3+} \cdot 3(\mathrm{n}-\mathrm{x}) \mathrm{Cl}^{-}\right\}^{3 \mathrm{x}+} \cdot 3 \mathrm{xCl}-
$$

Ионы железа (II) и $\mathrm{H}^{+}$, имея меньший заряд и, как следствие, меньшую адсорбционную способность, в процессе стабилизации участвуют незначительно.

Наиболее стабильные золи, содержащие наночастицы магнетита с минимальным значением гидродинамического диаметра и мономодальным их распределением (рис. 3), образуются 


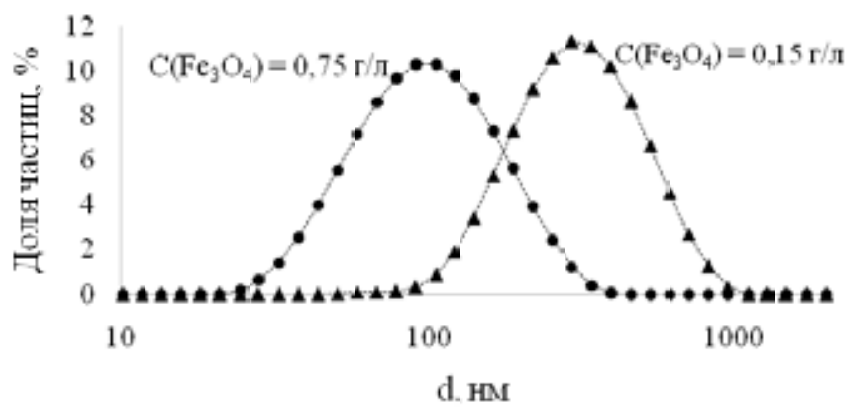

Рис. 3. Распределение по гидродинамическим диаметрам частиц магнетита, обработанных $\mathrm{HClO}_{4}$

Fig. 3. The distribution of the hydrodynamic diameters of magnetite particles treated with $\mathrm{HClO}_{4}$

при обработке исходного оксида хлорной кислотой, причем знак их поверхностного заряда зависит от $\mathrm{pH}$ дисперсионной среды. При $\mathrm{pH}=2,73$ мицеллы магнетита имеют положительный заряд, а при $\mathrm{pH}=3,15$ - отрицательный. Перезарядка поверхности частиц при разбавлении золя, вероятно, является следствием смены типа диссоциации поверхностных групп с основного на кислотный при прохождения системы через точку нулевого заряда, которая имеет величину, близкую к $\mathrm{pH}=3$. Из литературы [9] известно, что величина ТНЗ сильно зависит как от условий получения и обработки наночастиц, так и от состава дисперсионной среды, что согласуется с наблюдаемым смещением ТНЗ магнетита в область низких значений рН после их кислотной обработки. Формулу мицеллы золя, полученного после обработки магнетита раствором хлорной кислоты, можно представить следующим образом:

$$
\left\{\mathrm{m}\left(\mathrm{Fe}_{3} \mathrm{O}_{4}\right) \cdot \mathrm{nH}^{+} \cdot(\mathrm{n}-\mathrm{x}) \mathrm{ClO}_{4}^{-}\right\}^{\mathrm{x}} \cdot \mathrm{xClO}_{4}^{-} .
$$

Полученные стабильные золи магнетита, содержащие в зависимости от условий образования наночастицы с поверхностным зарядом разных знаков, подходят для дальнейшей функционализации за счет адсорбции различных противоионов с целью синтеза гибридных магнитных наночастиц.

\section{Выводы}

1. Методом математического планирования и обработки результатов экспериментов ДФЭ $2^{7-4}$ изучено влияние реакционных параметров (температура, время, концентрация и объем реагентов и др.) на химический состав образующихся наночастиц магнетита. В соответствии с полученным уравнением регрессии определены оптимальные условия процесса: $\mathrm{C}(\mathrm{NaOH})=6 \mathrm{M}$, молярное отношение $\mathrm{Fe}^{2+}: \mathrm{Fe}^{3+}=1: 2$, время синтеза в инертной атмосфере азота 1 ч при скорости продувания 20 пузырьков в минуту, время кипячения воды для приготовления щелочи и растворения навесок 1 ч при температуре $60^{\circ} \mathrm{C}$. По данным ПЭМ и РФА, полученные монофазные осадки содержат наночастицы магнетита кубической формы с размерами около 8-12 нм.

2. Изучено влияние предварительной обработки магнетита растворами сильных кислот на седиментационную и агрегативную устойчивости его гидрозолей и гидродинамический диаметр частиц. Установлено, что наиболее стабильные гидрозоли образуются при предварительной обработке магнетита раствором хлорной кислоты. Знак дзета-потенциала поверхности

$$
-107-
$$


полученных частиц определяется значениями $\mathrm{pH}$ дисперсионной среды. Обработка магнетита хлорной кислотой вследствие адсорбции протонов на его поверхности сдвигает значение ТНЗ оксида в область более низких значений $\mathrm{pH}(\approx 3)$.

\section{Благодарности / Acknowledgements}

В работе использованы приборы Красноярских региональных центров коллективного пользования ФИЦ КНЦ СО РАН и СФУ.

This work was conducted using the equipment of Krasnoyarsk Regional Research Equipment Centre of SB RAS and SFU.

\section{Список литературы / References}

1. Zhou Q., Wei Y. For better or worse, iron overload by superparamagnetic iron oxide nanoparticles as a MRI contrast agent for chronic liver diseases. Chem. Res. Toxicol. 2017. Vol. 30(1), P. 73-80.

2. Huang S., Meijia W. Magnetic nanoparticles in cancer diagnosis, drug delivery and treatment. Molecular and Clinical Oncology 2017. Vol. 7(5), P. 738-746.

3. Jolivet J-P. Interfacial electron transfer in colloidal spinel iron oxide. Conversion of $\mathrm{Fe}_{3} \mathrm{O}_{4}$ $\mathrm{Fe}_{2} \mathrm{O}_{3}$ in aqueous medium. J. Colloid and Interface Science 1988. V. 125, P. 688-701.

4. Xie X., Zhang X., Chen D., Fei W. Preparation and application of surface-coated superparamagnetic nanobeads in the isolation of genomic DNA. Journal of Magnetism and Magnetic Materials 2004. No. 277, P. 16-23.

5. Шапиро С.А. Аналитическая химия. М.: Высшая школа, 1973. 86 с. [Shapiro S.A. Analytical chemistry. Moscow: High School, 1973. 86 p. (In Russ.)]

6. Powder Diffraction File: база данных. - JCPDS 43 - 1458; 13-398.

7. Powder Diffraction File: база данных. - JCPDS $33-0664$.

8. Trofimova T.V., Saykova S.V., Saykova D.I., Chistyakov D.I. Synthesis of gold nanoparticles with anisotropy of the optical. Journal of Siberian Federal University. Chemistry 2016. Vol. 9(4), P. 496-503.

9. Сайкова С.В. Реакционно-ионообменные процессы извлечения цветных металлов и получения дисперсных материалов: Дис. ... д-ра хим. наук: 05.17.01. Красноярск, 2014. 303 с. [Saikova S.V. Reactive ion exchange processes of nonferrous metals leaching and dispersion material synthesis: doctoral dissertation: 05.17.01. Krasnoyarsk, 2014. 303 p. (In Russ.)]

10. Лунина М.А., Байбурутский Ф.С., Сенатская И.И. Основные закономерности агрегативной устойчивости и коагуляции лиофобных коллоидных систем. 10-я юбилейная международная Плесская конференция по магнитным жидкостям: сборник научных трудов, сентябрь 2002 г., Плес, ИГЭУ. Плес, 2002. С. 4-10. [Lunina M.A., Baiburutskii F.S., Senatskaya I.I. The basic patterns of aggregative stability and coagulation of lyophobic colloidal systems. The 10th Anniversary International Ples Conference on Magnetic Fluids: a collection of scientific papers, September 2002, Ples, ISPU. Ples, 2002. P. 4-10. (In Russ.)]

11. Sun Y.-K., Ming M., Zhang Y., Ning G. Synthesis of Nanometer-Size Maghemite Particles From Magnetite. Colloids and Surfaces A-physicochemical and Engineering Aspects. COLLOID SURFACE A. 2004. Vol. 245, P. 15-19. 